\title{
AVALIAÇÃO DA COMPOSIÇÃO CENTESSIMAL DE PEIXES COMERCIALIZADOS EM SUPERMERCADOS DE FORTALEZA-CE
}

\author{
SENA, D.N.; OLIVEIRA, A.F.R. \\ ${ }^{1}$ Aluna de graduação em Engenharia de Alimentos da UFC - Campus do Pici \\ E-mail: deborasnascimento@gmail.com
}

\begin{abstract}
RESUMO - A denominação genérica 'PESCADO' compreende os peixes, crustáceos, moluscos, anfíbios, quelônios e mamíferos de água doce ou salgada, usados na alimentação humana Alimentos marinhos são reconhecidos como uma boa fonte de proteínas para dieta. Assim, conhecer a composição centesimal de alimentos é de grande importância já que nos fornece a segurança do que está sendo consumido, além de, no Brasil, ser obrigatório que essas informações acompanhe todos os alimentos em forma de tabela. Assim, o trabalho buscou avaliar a composição centesimal em 4 amostras de peixes da espécie tilápia (Oreochromis) vendidos em supermercados de Fortaleza-CE para determinação do grau de frescor. Concluiu-se que de maneira geral os produtos apresentaram teores de proteína, lipídio, umidade e cinza de acordo com as medias encontradas em diversos estudos.
\end{abstract}

\section{INTRODUÇÃO}

Alimentos marinhos são reconhecidos como uma boa fonte de proteínas para dieta. Em algumas espécies os lipídios desempenham um importante papel nutricional, por sua atividade preventiva contra doenças cardiovasculares, interferir na produção de prostaglandinas e conhecidas ações vasculares e hemostáticas ( BUDOVSKI, 1981).

No entanto, $\mathrm{O}$ consumo de peixes ainda é baixo no Brasil, em torno de 6 $\mathrm{kg} /$ habitante/ano (Macedo-Viegas et al.,2000). Uma das maneiras de se reverter este quadro seria a circulação de informações sobre esses produtos e sua importância para a alimentação humana.

A criação de tilápias encontra-se amplamente distribuída no mundo inteiro, podendo atingir uma produção mundial de 1.500 .000 t em 2010, segundo. Por serem consideradas espécies de grande importância para a aqüicultura mundial, as tilápias são freqüentemente indicadas para a criação intensiva. A tilápia do Nilo (Oreochromis niloticus) destaca-se como uma das mais importantes, devido à sua alta taxa de crescimento, adaptabilidade em diversas 
condições e criação e boa aceitação pelo consumidor, principalmente pela excelente textura e pelo sabor de sua carne e ausência de espinhos intramusculares (SOUZA et. al., 2004)

A tilápia apresenta requisitos típicos dos peixes preferidos do consumidor, tais como carne branca de textura firme, sabor delicado e fácil filetagem, não tendo espinha em "Y" e nem odor desagradável. Possui também características que a colocam no pódio das principais espécies cultiva das comercialmente, como: facilidade de reprodução e obtenção de alevinos, a possibilidade de manipulação hormonal do sexo para produção de machos, aceitação de diversos alimentos, excelente crescimento em cultivo intensivo e resistência às doenças (SOUZA, 2002).

No Brasil, a expansão da tilápia tem sido impulsionada pela demanda de mercado por sua boa aceitação pela população, quanto ao sabor, valor nutritivo e preços baixos. O grande interesse pela tilápia também está nos piscicultores que a estão produzindo em todo o País, principalmente pela facilidade de cultivo, o que desperta o interesse das indústrias em processar este peixe (SIMÕES, 2007).

O valor nutritivo e os preços dos peixes dependem da textura da carne, da composição química, do rendimento e de fatores relacionados aos métodos de captura e beneficiamento. $\mathrm{O}$ conhecimento da composição química dos pescados é de fundamental importância para a padronização dos produtos alimentares na base de critérios nutricionais, pois fornece subsídios para decisões de caráter dietário, acompanhamento de processos industriais e seleção de equipamentos para otimização econômico-tecnológica (Contreras-Guzmán, 1994). Além disso, é a composição centesimal que nos fornece a segurança do que está sendo consumido.

Assim, o trabalho busca avaliar a composição centesimal de peixes, da espécie tilápia (Oreochromis), comercializados em supermercados da região de Fortaleza-CE.

\section{METODOLOGIA}

Foram avaliadas ao todo 4 amostras de peixe da espécie tilápia (Oreochromis). As amostras foram compradas em supermercados da cidade de Fortaleza - CE, todas vendidas como produto fresco, todas as amostras estavam evisceradas. Os mesmos foram armazenados em refrigerador doméstico a temperatura média de $0^{\circ} \mathrm{C}$ antes 
deserem avaliadas, o transporte foi realizado em tempo hábil para não interferir nas analises de qualidade do pescado.

$\mathrm{O}$ teor de umidade foi analisado, pesando $5 \mathrm{~g}$ das amostras em cadinhos previamente aquecidos em estufa a $60^{\circ} \mathrm{C}$ por uma hora, resfriados em dessecador $\mathrm{e}$ pesados, estas amostras foram submetidas à secagem em estufa a $105^{\circ} \mathrm{C}$ por aproximadamente 24 horas, resfriadas em dessecador a temperatura ambiente e pesadas até se obter peso constante.

Para analise de cinzas, pesou-se aproximadamente $0,5 \mathrm{~g}$ da amostra em cadinhos previamente aquecidos em estufa a $60 \%{ }^{\circ} \mathrm{C}$ por uma hora, resfriados em dessecador e pesados. Estas amostras foram calcinadas a $550^{\circ} \mathrm{C}$, por aproximadamente uma hora, até atingir cinzas brancas. Os cadinhos foram resfriados em dessecador e pesados, e o teor de cinzas expresso em $\mathrm{g}$ cinzas $100^{-1} \mathrm{~g}$ de amostra.

Os teores de proteínas foram determinados usando como solução extratora biftalato de potássio e fenolftaleína como indicador, a solução foi titulada com $\mathrm{NaOH}$ utilizando agua destilada como teste branco.

$\mathrm{Na}$ determinação dos teores de lipídio foi realizada em cartuchos de papel de filtro Whatman utilizando a amostra seca, adicionando-se $100 \mathrm{ml}$ de hexano. Ligou-se o sistema de extração e o deixou em refluxo por 6 horas. Recuperou-se o hexano até o balão secar. Colocou-se o balão em estufa a $105^{\circ} \mathrm{C}$ por 2 horas e depois os esfriou em dessecador. Foi repetido a operação até peso constante.

\section{RESULTADOS E DISCURSÕES}

Ao analisarmos a tabela 1, que apresenta a composição centesimal das amostras de tilápia, observamos que as amostras apresentaram média de 77,61\% de umidade, esse valor é semelhante ao encontrado por Caula et. al. (2008), em estudo sobre teor de colesterol e composição centesimal de algumas espécies de peixes do estado do Ceará encontrou médias de umidade de $80,7 \%$ para o pargo e $80,2 \%$ para a tilápia.

Tabela 1 - Composição Centesimal das Amostras de Tilápia 


\begin{tabular}{ccccccc}
\hline \hline & A & B & C & D & Média & Desv. Padrão \\
\hline Umidade (\%) & 77,78 & 77,45 & 77,23 & 77,98 & 77,61 & 0,33 \\
Cinza (\%) & 1,23 & 1,09 & 1,15 & 1,16 & 1,16 & 0,06 \\
Proteina (\%) & 13,2 & 13,34 & 13,7 & 13,5 & 13,44 & 0,22 \\
Lipídios (\%) & 1,38 & 1,06 & 1,05 & 0,98 & 1,12 & 0,18 \\
\hline \hline
\end{tabular}

Quanta aos teores de cinza, as amostras apresentaram em média 1,16\%. Segundo Stansby (1962), os teores de cinza em pescado deve variar entre 0,4 e 1,5\%, assim, as amostras apresentaram conformidade.

As amostras apresentaram teores médios de proteína de 13,44\%, a composição protéica da carne de peixe pode variar em função da espécie, do tamanho, do sexo e da época do ano; porém, geralmente, o músculo contém cerca de $20 \%$ de proteína. Nota-se pelos dados na Tabela 1 que os teores de proteína nas amostras ficaram compreendidos na faixa de publicados pela literatura brasileira e internacional (CAULA et. al., 2008).

Quanto ao teor de lipídio, as amostras apresentaram baixo teor de lipídio total, com média de $1,12 \%$. Com base nos teores de lipídio encontrados no presente estudo, podemos classificar as amostras como pescado de baixo conteúdo de gordura visto que apresentaram menos que $2 \%$ de conteúdo de lipídeos (PIGOTT e TUCKER, 1990). Ainda Caula et. al. (2008), em seu estudo encontrou teor de lipídio de 1,2\% para tilápia, valores estes semelhantes ao encontrado no presente trabalho.

Os dados apresentados na tabela 1 mostram que não houve uma variação significativa entre as amostras analisadas visto que os valores de desvio padrão encontrados não chegaram a $0,5 \%$. Alem disso, os resultados foram próximos aos encontrados por YANAR et al. (2006) em estudos também sobre tilápia que apresentou $76,87 \%$ de umidade, $18,23 \%$ de proteína, 2,64\% de lipídios e 1,09\% de cinza. Estes resultados também concordam com os encontrados por SALES e SALES (1990) para tilápia, nesse estudo as amostras apresentaram valores de umidade $75 \%, 18,5 \%$ de proteína, $3,60 \%$ de lipídios e $2,4 \%$ de cinzas. 


\section{CONCLUSÕES}

Concluímos com o presente trabalho que alimentos marinhos são reconhecidos como uma boa fonte de proteínas e lipídios para dieta humana.

Além disso, entendeu-se que conhecer a composição centesimal do pescado é de extrema importância para se estabelecer dietas e metas nutricionais, e para que as pessoas possam saber o que contém o alimento que estão para consumindo.

Concluiu-se ainda que as amostras apresentaram teores médios de composição centesimal dentro dos parâmetros exigidos aos valores presentes na literatura para essa espécie de peixe.

\section{REFERÊNCIAS BIBLIOGRÁFICAS}

BUDOVSKI, P. Fish and the cardiovascular system. Progress Food Nutrition Science, Oxford, v.17, p.223-231, 1981.

CONTRERAS-GUZMÁN, E.S. Bioquímica de pescados e derivados. Jaboticabal: FUNEP, 1994.

MACEDO-VIEGAS, E.M.; SOUZA, M.L.R; BACCARIN, A.E.et al. Aspectos mercadológicos de pescados e derivados em algumas cidades das regiões sul e sudeste do Brasil. Infopesca Internacional, v.6, p.13-22, 2000.

PIGOT, G; TUCKER, B. Sea food effects of technology on nutrition, 1st edit, Edit Marcel Dekker, INC, New York, USA, 1990.

SALES, R. de O., SALES, A. M.; Estudo da composição química e rendimento de dez espécies de água doce de interesse comercial nos açudes do nordeste brasileiro. Ciências Agronômicas. v. 1, n. 21, p. 27-30, 1990.

SIMÕES,M.R.; RIBEIRO,C.F.A.; RIBEIRO, S.C.A.; PARK, K.J.; MURR,F.E. Composição físico-química, microbiológica e rendimento do filé de tilápia tailandesa (Oreochromis niloticus). Ciênc. Tecnol. Aliment., Campinas, 27(3): 608-613, jul.-set. 2007.

CAULA,F.C.B.; OLIVEIRA,MP.; MAIA,E.L. Teor de colesterol e composição centesimal de algumas espécies de peixes do estado do Ceará. Ciênc. Tecnol. Aliment., Campinas, 28(4): 959-963, out.-dez. 2008.

PIGOT, G; TUCKER, B. Sea food effects of technology on nutrition, 1stedit, Edit Marcel Dekker, INC, New York, USA, 1990. 
SOUZA, M. L. R. Comparação de Seis Métodos de Filetagem, em Relação ao Rendimento de Filé e de Subprodutos do Processamento da Tilápia-do-Nilo (Oreochromis niloticus). Revista Brasileira de Zootecnia., v. 31, n. 3, p. 1076-1084, 2002.

SOUZA,L. M.R.; BACCARIN,A.E.;VIEGAS,E.M.M.;KRONKA,S.N. Defumação da Tilápia do Nilo (Oreochromis niloticus) Inteira Eviscerada e Filé: Aspectos Referentes às Características Organolépticas, Composição Centesimal e Perdas Ocorridas no Processamento. R. Bras. Zootec., v.33, n.1, p.27-36, 2004.

STANSBY, M. E. Proximate composition of fish. In: HEEN, E.; KREUZER, R. (Ed.). Fish in nutrition. London: Fishing News, 1962. p. 55-60.

YANAR Y.; CELIK, M.; AKAMCA, E. Efects of brine concentration on shelf-life of hotsmoked tilapia (Oreochromis niloticus) stored at $4{ }^{\circ} \mathrm{C}$. Food Chemistry v. 97, n. 2 p. 244247, 2006. 